\title{
Comparative Assessment of Problem Based and Web- based Learning in Neurophysiology
}

Varghese Anne ${ }^{1, *}$, Celine $^{2}$

\section{Varghese Anne ${ }^{1, *}$, Celine $^{2}$}

'Department of Physiology, MOSC Medical College, Kolenchery, Kerala-682311, INDIA.

${ }^{2}$ Department of Community Medicine, MOSC Medical College, Kolenchery, Kerala-682311, INDIA.

\section{Correspondence}

\section{Dr. Anne Varghese}

Department of Physiology, MOSC Medical College, Kolenchery, Ernakulam, Kerala-682311, INDIA.

Phone: +919447434345

Email: annesunil4@gmail.com

\section{History}

- Submission Date: 18-09-2018

- Review completed: 05-11-2018;

- Accepted Date: 02-12-2018.

DOI : 10.5530/ijcep.2018.5.4.19

Copyright

(C) 2018 Phcog.Net. This is an openaccess article distributed under the terms of the Creative Commons Attribution 4.0 International license.

\begin{abstract}
Background and Aim: Neurophysiology concepts are difficult to understand in the first hearing and to apply in clinical situations too. To fill this gap, the teaching- learning methods have to be modified. This study introduces two learning methods in this scenario and comparatively assesses them. The objective of the study was to compare the problem- based and web - based learning methods in Neurophysiology. And To find the effects of problem- based and web - based learning methods. Methods: The quasi-experimental study was carried out on I MBBS students of MOSC Medical College, Kolenchery, who were divided randomly into two groups: Problem-based Learning group (PBL) and Web-based Learning (WBL) group. Pre and Post- test were administered to the two groups and individual feedback was collected online. Results: The pre and post test marks in the 2 groups did not show any significant difference by Wilcoxon Signed Rank Test ( $p=0.636$ for the PBL group and $p=0.051$ for the WBL group). Inter-group Post-test score comparison by Mann-Whitney $U$ test gave a non-significant result ( $p$-value $=0.056$ ). Conclusion: This indicates that there is no significant intra- or inter- group improvement in the scores obtained. Feedback responses collected from both groups showed proportionately higher number of students wanting more topics to be taken in a similar manner.
\end{abstract}

Key words: Problem-based Learning (PBL), Web-based Learning (WBL), Neurophysiology.

\section{INTRODUCTION}

Neurophysiology concepts have often been found to be difficult by students in terms of understanding and at application level. Hence simplifying it and making it more understandable has always been a challenge. Innovative methods like Problem Based Learning (PBL) and Web- Based Learning (WBL) can be tested for its scope in improvement of this understanding. PBL was first introduced in Harvard Medical School curriculum in $1987^{[1]}$ and aimed at 'learning through discovery'. Paper based PBL scenarios form the basis of the core curriculum and ensure that all students are exposed to the same problems being used as the stimulus for learning. ${ }^{[2]}$ With technological development, Web -based Learning (WBL) makes learning content more accessible. In medical education, the web is increasingly used both as a learning tool to support conventional curricular programmes which are more formal in nature and as a means of delivering online learning programme. As students are usually addressed in large groups for pre-clinical teaching, web based learning can be used to provide learning materials to complement conventional programmes. ${ }^{[3]}$

Many related studies have proven the effectiveness of online learning and problem- based learning. The effectiveness of PBL has been debated ${ }^{[4-6]}$ over the years. However, meta- analysis studies have favoured

its usage as a tool for effective and proper training. ${ }^{[7]}$ Web- based learning on the other hand has received more positive reviews ${ }^{[8]}$ Meta-analysis studies opine that educators making decisions about online learning need rigorous research examining the effectiveness of online learning for different types of students and subject matter as well as studies of the relative effectiveness of different online learning practices. ${ }^{[9]}$

With this background, the humble effort here is to combine the best features of in- class teaching with online learning and with problem- based learningcomparing the two and assessing student learning in neurophysiology by these two methods. Therefore the objective of the present study was to compare the problem- based and Web - based learning methods in learning neurophysiology, to find the effect of Problem-based learning in the problem based learning group and to find the effect of Web -based learning in the web based learning group.

\section{MATERIALS AND METHODS}

The present work was a Quasi-experimental study conducted in the department of Physiology MOSC Medical College, Kolenchery, Kerala for a period of 3 months ( 2 months sample collection and 1 month data analysis) from November 2017 to January 2018. The study participants included all $1^{\text {st }}$ Semester

Cite this article: Anne V, Celine. Comparative Assessment of Problem Based and Web-based Learning in Neurophysiology. Int J Clin Exp Physiol. 2018;5(4):184-8. 
MBBS students of 2017-2018 regular batches. The project proposal was submitted before the Institutional Review Board and Institutional Ethics Committee, which scrutinized it and gave approval for the conduct of the study (Protocol No: MOSC/IEC/259/2017 dated17/11/2017). Informed consent was obtained from all willing participants.

The sample size includes all the students admitted for I MBBS as per university norms, which is, 100 students. A 2 hr lecture session is conducted on a relevant neurophysiology topic for all participants of the study. The topic chosen was Synaptic inhibition. After a gap of about 2 weeks, the students were divided into two groups of 50 each. Each batch of 50 students was divided into 2 groups: 25 students were taken into one group and 25 into another group, based on their roll number. From the two groups, one group was randomly selected; this group selected its leaning method using lots, while the other group was assigned the other learning method. Thereafter, both groups were administered the Pre-test MCQ Questionnaire. The subject- based peer-reviewed MCQ questionnaire has 10 questions of varying difficulty level. One student group is exposed to the Problem- based Learning (PBL) method on Synaptic inhibition where there is discussion between faculty and students on clinical-situation based question cards. The other student group is exposed to the same topic, at the same time, by the Web-based Learning (WBL) method. Study content on the same topic is provided online which the students view in the department within a specified time period. There is no direct faculty involvement here; however they can interact among themselves. Post-test MCQ questionnaire is administered under faculty supervision to both the student groups soon after the intervention. A cross- over of the groups is done following this in order to address ethical concerns and so that none of the students miss out any content. Data collected are the pre-test and post test scores of the MCQ questionnaire and feedback about reaction to the study. Data tabulation and analysis is done using Microsoft Excel 2010. Feedback responses were collected from both groups through online 'Survey Monkey' which applies the 5-point Likert scale for assessment of responses.

\section{Statistical analysis of data}

Wilcoxon's Signed Rank Test was used for comparing the pre and post test scores and Mann- Whitney U test for the comparison of post-test scores of the two groups.

\section{RESULTS}

Of a possible 100 students only 73 could be recruited for the study the reason being absenteeism from class. Of the 73 students, 29 students among the PBL group and 44 students among the WBL group were present at the time of the study, the others being absent at that time. The outcome variables of the two groups are the marks obtained in the tests and the score value on the feedback form. Pre test scores of students in the $\mathrm{PBL}$ group and WBL group showed no significant difference ( $p$-value of 0.566 ), indicating that the two groups were comparable based on their performance in the MCQ questionnaire. Post- test scores of students in the two groups were not significantly different ( $p$-value of 0.056 ). No significant difference was found in the pre and post test scores of students in the PBL group ( $p$-value of 0.636 ) and WBL group ( $p=0.051)$. A study of the descriptive statistics makes these aspects clear as shown in Table 1 Feedback responses on the online 'Survey Monkey' response form were collected from both groups. A 5- point Likert scale (Annexure) was used, the results of which are displayed in Table 2 . Of the 73 participants, only $27(37 \%)$ responded to the online feedback survey. Hence the feedback data has not been studied in depth with respect to the two groups (PBL and WBL). Of the 27 responders to the feedback survey, 23 answered to the question regarding utility of such interventions in the future. 19
Table 1: Descriptive Statistics. Quartile distribution of Pre and Post- Test scores in the study groups: PBL and WBL.

\begin{tabular}{|c|c|c|c|c|c|c|}
\hline \multirow[b]{3}{*}{ PBL } & \multicolumn{2}{|c|}{$\begin{array}{c}\text { First Quartile } \\
\left(25^{\text {th }} \text { percentile) }\right.\end{array}$} & \multirow{2}{*}{\multicolumn{2}{|c|}{$\begin{array}{c}\text { Median } \\
\text { (50 } 0^{\text {th }} \text { percentile) } \\
\text { Pre-test Post-test }\end{array}$}} & \multirow{2}{*}{\multicolumn{2}{|c|}{$\begin{array}{c}\text { Third Quartile } \\
\left(75^{\text {th }} \text { percentile) }\right. \\
\text { Pre-test Post-test }\end{array}$}} \\
\hline & Pre-test & Post-test & & & & \\
\hline & 5.5 & 6 & 7 & 6 & 7 & 7 \\
\hline WBL & 5 & 6 & 6.5 & 7 & 7 & 8 \\
\hline
\end{tabular}

The median values show a slight increase in post- test scores compared to those of pre-test in the WBL group.

\section{Proportion of Studentsinfavour of Intervention}

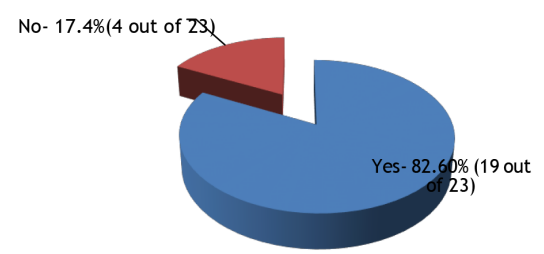

Figure 1: Pie chart showing the proportion of feedback responders in favour of intervention.

Table 2: Feedback response data.

\begin{tabular}{lccccc} 
& \multicolumn{5}{c}{ Percentage of responses } \\
\multicolumn{1}{c}{ Likert Scale 1-5 ${ }^{\text {a }}$} & 1 & 2 & 3 & 4 & 5 \\
$\begin{array}{l}\text { 1. How clearly did your } \\
\text { instructor explain the course } \\
\text { material? }\end{array}$ & $11.1 \%$ & $55.6 \%$ & $29.6 \%$ & $3.7 \%$ & $0 \%$ \\
$\begin{array}{l}\text { 2. How well-organized was the } \\
\text { course? }\end{array}$ & $11.5 \%$ & $53.9 \%$ & $30.8 \%$ & $3.9 \%$ & $0 \%$ \\
$\begin{array}{l}\text { 3. How worthwhile } \\
\text { was the course material? }\end{array}$ & $11.54 \%$ & $46.2 \%$ & $23.1 \%$ & $19.2 \%$ & $0 \%$ \\
$\begin{array}{l}\text { 4. Was the course too } \\
\text { challenging, too easy, or about } \\
\text { right? }\end{array}$ & $0 \%$ & $15.4 \%$ & $84.6 \%$ & $0 \%$ & $0 \%$ \\
$\begin{array}{l}\text { 7. How well does the course } \\
\text { meet your needs? }\end{array}$ & $11.5 \%$ & $46.2 \%$ & $34.6 \%$ & $7.7 \%$ & $0 \%$ \\
$\begin{array}{l}\text { 8. Was the speed with which } \\
\text { your instructor presented the } \\
\text { course material too fast, too } \\
\text { slow, or about right? }\end{array}$ & $3.9 \%$ & $26.9 \%$ & $69.2 \%$ & $0 \%$ & $0 \%$ \\
\hline
\end{tabular}

Footnote: 'a': the Likert scales 1 to 5 have been described in the Questionnaire

out these 23 students (82.6\%) favoured and preferred more topics to be taken using these learning methods. This has been represented in Figure 1. The feedback response on 'specific problems encountered by the students during execution of the program' pointed out less time availability to study the content and the need for more explanation of concepts.

\section{DISCUSSION}

Didactic lectures were the conventional method of conveying information and still continue to be so. However, following the adoption of 
CBME by many countries world- over, the stress has slowly been more on newer and innovative teaching methods like Problem based Learning (PBL) and utilization of modern resources like Web- based Learning (WBL). These innovative methods help in the improvement of the overall performance, conceptual and procedural knowledge in the participants compared to conventional instructional methods. ${ }^{[10,11]}$

In this study, the pre-test scores of the 2 groups were analysed and the groups were found to be comparable. The intervention was done thereafter and post-test was conducted. Statistic analysis of the intra and intergroup scores did not yield any statistically significant result, indicating that the student learning outcome is not significantly modified by the intervention. Difficulty level of the topic and level of understanding following lecture sessions are two major factors that can influence the student learning outcome in such interventions.

PBL is defined by Howard Barrows as a learning method which involves student centred learning in small groups lead by an "expert", rather than teaching using the traditional lecture. Studies reveal that PBL is mainly promoted in medical schools as the best method to foster learning through discovery. This is called the 'contructivist' approach of PBL and it motivates the student to learn and acquire new information. The curiosity of the student should be aroused for effective teaching. Biggs and Tang ${ }^{[12]}$ define effective teaching as one that "gets most students to use the level of cognitive processes needed to achieve intended outcomes that the more academic students use spontaneously". This implies that a cognitively more-challenging topic is one that is most suitable for the PBL approach. On the other hand, studies reveal more critical problems associated with PBL implementation. John Sweller, ${ }^{[13]}$ Woei Hung, ${ }^{[14]}$ Newman ${ }^{[15]}$ and Graham Parton and Richard Bailey ${ }^{[16]}$ have propounded a variety of such crucial problems. The main criticism is that it is not suitable or applicable for all types of education and is learner and content- variable.

In Web- based Learning (WBL), the physical role of the facilitator is replaced by technology driven facilitator. Contents are displayed on screen and student follows it at a pace decided by him. Barrows and Tamblyn ${ }^{[17]}$ believed that the facilitator should have 'process expertise' rather than 'content expertise'. Another factor is that the facilitator's specialist knowledge helps students especially when curriculums are too poorly designed for the students' level of learning. The personal qualities of the facilitator could be the best to motivate students. ${ }^{[18-20]}$ However, the advantages of a purely student- driven WBL that involves self-directed learning are yet to be tapped fully. Among the feedback responders, a higher proportion was seen to favour interventional and interactive sessions of both PBL and WBL types.

\section{LIMITATIONS OF THE STUDY}

On the day of one session, the non-participants were absentees eager to go home for holidays. The timing of the study could have been better suited to the students' schedule. This resulted in skewing of the participants towards one group. However, in spite of this, the study had to be carried on forward to ensure non- leakage of the subject based MCQ questions. The feedback to the study was done by online method, but seeing the poor response, other methods of feedback collection could have been utilised. The time given to the students to study the online content was insufficient and the time for online study was practically inflexible and decided by the teacher and not the student himself/herself. This pattern was purposefully adopted to ensure equal student opportunity and to ensure the confidentiality of the MCQ test questionnaire.

\section{CONCLUSION}

A total 73 students took part in the study, out of a possible 100. Pretest score analysis showed that the 2 groups were comparable. An inter- group (PBL and WBL) Post- test score comparison did not reveal any significance. Those in the WBL group showed a slightly better post-test score compared to the pre-test score which was however statistically insignificant $(p=0.051)$. Inter-group Post-test score comparison gave a non-significant $p$-value of 0.056 . Feedback responses collected from both groups showed proportionately higher number of students wanting more topics to be taken in a similar manner. Though the study does not reveal a significantly favourable student learning outcome towards either type of intervention, the students' attitude in favouring intervention is proportionately higher. This study is relevant in the context of introduction of Competency Based Medical Education in the field of Medical Education in India.

\section{ACKNOWLEDGEMENT}

I would like to thank all my dear students who participated in this study and encouraged me.

This project was undertaken as part of the stipulations of the Advanced Course in Medical Education conducted by the Medical Council of India under the aegis of the MEU Nodal Centre, Govt. Medical College, Kottayam, Kerala. The project was critically mentor-reviewed and peerreviewed at multiple levels. I would like to acknowledge the support and cooperation extended by the mentors at the MEU Nodal Centre, Govt. Medical College, Kottayam and faculty of Physiology Department, MOSC, in helping me execute my project.

\section{CONFLICT OF INTEREST}

The authors report no external funding source for this study.

\section{ABBREVIATIONS}

PBL: Problem Based Learning; WBL: Web Based Learning; MCQ: Multiple Choice Questions; CBME: Competency Based Medical Education; MEU: Medical Education Unit.

\section{SUMMARY}

Neurophysiology concepts are difficult to understand in the first hearing and to apply in clinical situations too. To fill this gap, the teaching- learning methods have to be modified. This study introduces two learning methods in this scenario and comparatively assesses them. The objective of the study was to compare the problem- based and web - based learning methods in Neurophysiology. And To find the effects of problem- based and web - based learning methods. The quasi-experimental study was carried out on I MBBS students of MOSC Medical College, Kolenchery, who were divided randomly into two groups: Problem-based Learning group (PBL) and Web-based Learning (WBL) group. Pre and Post- test were administered to the two groups and individual feedback was collected online. Results: The pre and post test marks in the 2 groups did not show any significant difference by Wilcoxon Signed Rank Test $(p=0.636$ for the PBL group and $p=0.051$ for the WBL group). Inter-group Posttest score comparison by Mann-Whitney $U$ test gave a non-significant result ( $p$-value $=0.056)$. Conclusion: This indicates that there is no significant intra- or inter- group improvement in the scores obtained. Feedback responses collected from both groups showed proportionately higher number of students wanting more topics to be taken in a similar manner.

\section{REFERENCES}

1. Srinivas SM, Medina-Martinez N, Howell TW, Karimbux NY. Problem-Based Learning: Effects on Standard Outcomes. J Dent Educ. 2003;67(9):1003-10.

2. Wood DF. ABC of learning and teaching in medicine: Problem based learning. BMJ. 2003;326(7384):328-30

3. McKimm J, Jollie C, Cantillon P.Web based learning. BMJ. 2003;326(7394):870- 
4. Colliver JA. Effectiveness of Problem-based Learning Curricula: Research and Theory. Acad Med. 2000;75(3):259-66.

5. Chang G, Cook D, Maguire T, et al. Problem-based learning: its role in undergraduate surgical education. Can J Surg. 1995;38(1):13-21.

6. Albanese M. Problem-based learning: why curricula are likely to show little effect on knowledge and clinical skills. Med Educ. 2000;34(9):729-38.

7. Sayyah $M$, Shirbandi $K$, et al. Use of a problem-based learning teaching model for Undergraduate medical and nursing education: a systematic review and meta-analysis. Adv Med Educ Pract. 2017;8:691-700.

8. Housego S, Freeman M. Case studies: Integrating the use of web based learning systems into student learning. Educ Tech. 2000;16(3):258-82.

9. Means B, Toyama Y, et al. Evaluation of Evidence-Based Practices in Online Learning: A Meta-Analysis and Review of Online Learning Studies. U.S. Department of Education Washington D.C. 2010.

10. Bayat S, Tarmizi RA. Effects of problem-based learning approach on cognitive variables of university students. Procedia - Social and Behavioral Sciences. 2012;46:3146-51

11. Albanese MA, Mitchell S. Problem-based learning: A review of literature on its outcomes and implementation issue. Acad Med. 1993;68:52-81.

12. Biggs J, Tang C. Teaching for Quality Learning at University. McGraw-Hill Inter- national. 2011.

13. Sweller J. Cognitive Load During Problem Solving: Effects on Learning. Cognitive Science. 1988;12(2):257-85

14. Hung W, Jonassen DH, Liu R. All Problems are Not Equal: Implications. for Problem-Based Learning. Interdisciplinary Journal of Problem-Based Learning. 2008;2(2).

15. Newman MJ. Problem Based Learning: an introduction and overview of the key features of the approach. J Vet Med Educ. 2005;32(1):12-20.

16. Parton G, Bailey R. Problem-based learning: a critical rationalis perspective. London Review of Education. 2008;6(3)281-92.

17. Barrows HS, Tamblyn RM. Problem-based learning: an approach to medical education. Medical education, New York: Springer. 1980;1.

18. DeVolder ML. Discussion groups and their tutors: relationships between tutor characteristics and tutor functioning. Higher Educ. 1982;11(3):269-71.

19. Schmidt HG. Resolving inconsistencies in tutor expertise research: does lack of structure cause students to seek tutor guidance?. Acad Med. 1994;69:656-62.

20. Rostas J, Olson L. Making it work. Imperatives in medical education: the Newcastle approach. 1997:84-97.

Cite this article: Anne V, Celine. Comparative Assessment of Problem Based and Web-based Learning in Neurophysiology. Int J Clin Exp Physiol. 2018;5(4):184-8. 


\section{APPENDIX}

\section{Tools for the study}

A. MCQ Questionnaire based on the topic of Synaptic inhibition, consisting of 10 single- response multiple choice questions of variable difficulty level

B. Feedback response Questionnaire:

1. How clearly did your instructor explain the course material?

1-Extemely clearly

2-Very clearly

3-Somewhat clearly

4- Not so clearly

5- Not at all clearly

2. How well-organized was the course?

1-Extremely well-organized

2-Very well-organized

3-Somewhat well-organized

4-Not so well-organized

5-Not at all well-organized

3. How worthwhile was the course material?

1-Extremely worthwhile

2-Very worthwhile

3-Somewhat worthwhile

4-Not so worthwhile

5-Not at all worthwhile
4. Was the course too challenging, too easy, or about right?

1-Much too challenging

2-Too challenging

3-About Right

4-Too easy

5-Much too easy

5. Would you like any more topics to be discussed in this manner?

1 -Yes

2 -No

6. Do you have any other comments, questions, or concerns?

7. How well does the course meet your needs?

1-Extremely well

2-Very well

3-Somewhat well

4-Not so well

5-Not at all well

8. Was the speed with which your instructor presented the course material too fast, too slow, or about right?

1-Much too fast

2-Too fast

3-The right amount

4-Too slow

5-Much too slow

Please describe the problem you encountered in more detail. 